\title{
Teaching NeuroImages: Vertebral artery atlas loop dissection in 3D T1 MRI multiplanar reconstruction
}

Georgios Tsivgoulis, MD, PhD, FESO, Georgios N. Papadimitropoulos, MD, Stefanos Lachanis, MD, Lina Palaiodimou, MD, Christina Zompola, MD, Paschalis Zervas, MD, and

Konstantinos Voumvourakis, MD, PhD

Neurology ${ }^{\circledR}$ 2018;91:e599-e600. doi:10.1212/WNL.0000000000005947
Correspondence

Dr. Papadimitropoulos

ge.papadim@gmail.com

Figure 1 Left dorsolateral medullary stroke
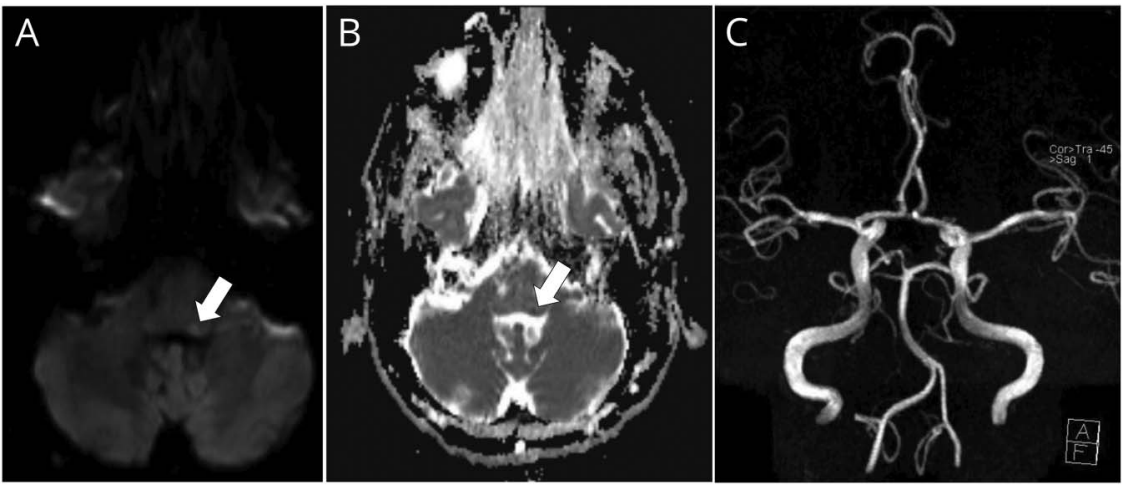

(A) Diffusion-weighted MRI shows a dorsolateral medullary infarct (arrow). (B) Apparent diffusion coefficient map confirms true diffusion restriction (arrow). (C) Time-of-flight magnetic resonance angiography without visible vascular pathology. V2 and V3 segments of vertebral arteries not covered in imaged volume.

A 38-year-old woman presented with left-sided ataxia and a minor ischemic lesion of the left dorsolateral medulla was found on brain MRI. Magnetic resonance angiography was unremarkable (figure 1, A-C). A 3D fat-saturated black-blood 3T T1-weighted sequence (sampling perfection with application-optimized contrast using different flip-angle evolutions [SPACE] ) revealed a mural hematoma of the V3 left vertebral artery segment, along the atlas loop (figure 2, A-C, arrows). The excellent volume coverage and mural/luminal distinction characteristics of the SPACE sequence ${ }^{1}$ allowed the clear depiction of vertebral artery dissection and consequent luminal stenosis, highlighting the need for high-resolution vertebral arteries imaging, particularly in young adult stroke patients. ${ }^{2}$

\section{Author contributions}

Georgios Tsivgoulis: data collection, study design, drafting and revising the manuscript. Georgios N. Papadimitropoulos: drafting and revising the manuscript. Stefanos Lachanis: data collection, critical comments during manuscript revision. Lina Palaiodimou: data collection, critical comments during manuscript revision. Christina Zompola: data collection, critical comments during manuscript revision. Paschalis Zervas: data collection, critical comments during manuscript revision. Konstantinos Voumvourakis: critical comments during manuscript revision.

\section{Study funding}

Dr. Tsivgoulis was supported by European Regional Development Fund, Project FNUSAICRC (No. CZ.1.05/1.1.00/02.0123).

\section{MORE ONLINE}

$\rightarrow$ Teaching slides

links.lww.com/WNL/

A614

From the Second Department of Neurology (G.T., G.N.P., L.P., C.Z., P.Z., K.V.), National and Kapodistrian University of Athens, School of Medicine, "Attikon" University Hospital, Greece; Department of Neurology (G.T.), The University of Tennessee Health Science Center, Memphis; International Clinical Research Center (G.T.), Department of Neurology, St. Anne's University Hospital in Brno, Czech Republic; and latropolis Magnetic Resonance Diagnostic Centre (S.L.), Athens, Greece.

Go to Neurology.org/N for full disclosures. Funding information and disclosures deemed relevant by the authors, if any, are provided at the end of the article. 
Figure 2 Left vertebral artery V3 segment dissection on T1 sampling perfection with application-optimized contrast using different flip-angle evolutions MRI at 3T
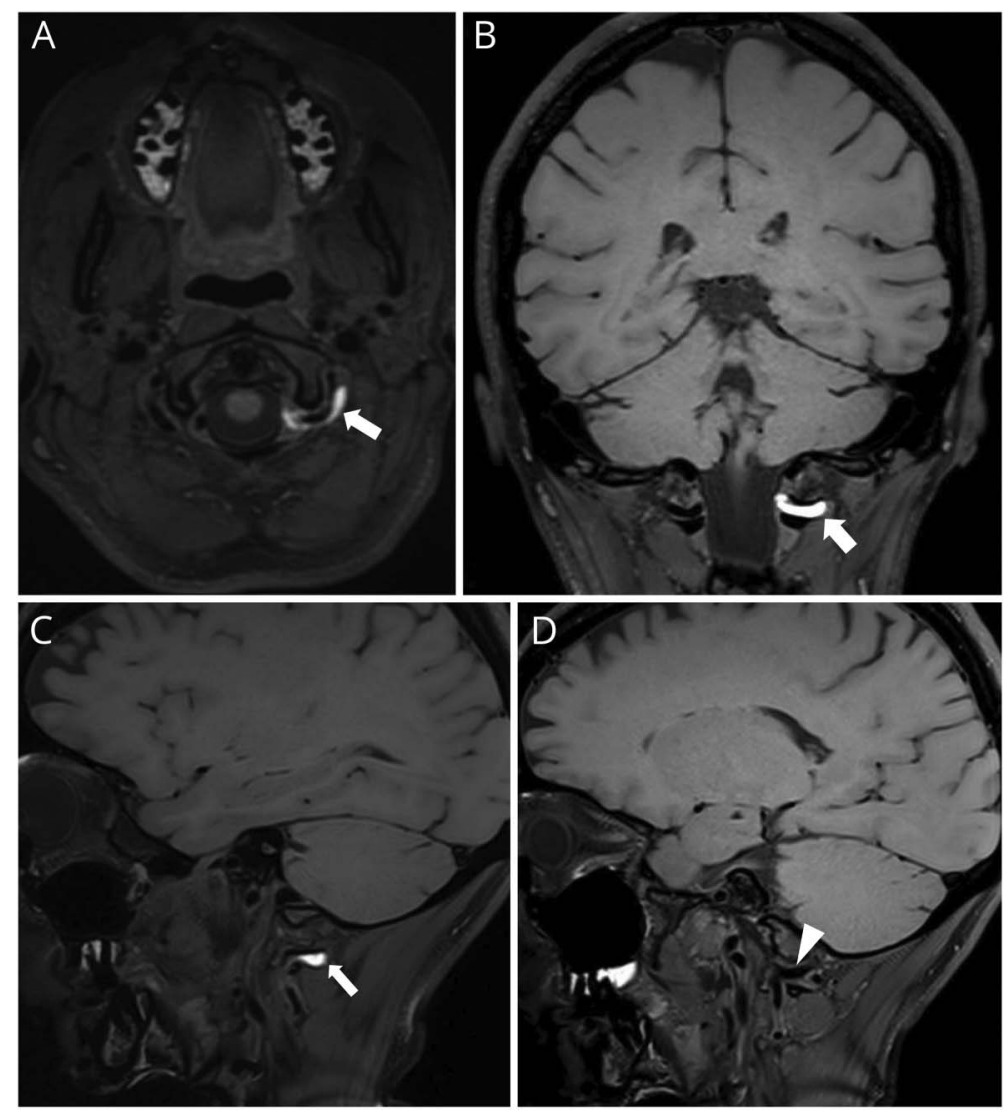

Multiplanar reconstruction. High-intensity signal represents subacute intramural hematoma (A-C, arrows) along V3 segment of left vertebral artery. Hematoma visibly restricts vertebral artery lumen diameter. Compare unaffected contralateral lumen diameter (e.g., D, arrowhead). (A) Axial plane. (B) Coronal plane. (C) Left parasagittal plane. (D) Right parasagittal plane.

\section{Disclosure}

The authors report no disclosures relevant to the manuscript. Go to Neurology.org/N for full disclosures.

\section{References}

1. Cuvinciuc V, Viallon M, Momjian-Mayor I, et al. 3D fat-saturated T1 SPACE sequence for the diagnosis of cervical artery dissection. Neuroradiology 2013;55:595-602.

2. Arnold M, Bousser MG, Fahrni G, et al. Vertebral artery dissection: presenting findings and predictors of outcome. Stroke 2006;37:2499-2503. 


\section{Neurology}

\section{Teaching NeuroImages: Vertebral artery atlas loop dissection in 3D T1 MRI multiplanar reconstruction}

Georgios Tsivgoulis, Georgios N. Papadimitropoulos, Stefanos Lachanis, et al. Neurology 2018;91;e599-e600

DOI 10.1212/WNL.0000000000005947

This information is current as of August 6, 2018

\section{Updated Information \& Services}

References

Subspecialty Collections

Permissions \& Licensing

Reprints including high resolution figures, can be found at: http://n.neurology.org/content/91/6/e599.full

This article cites 2 articles, 1 of which you can access for free at: http://n.neurology.org/content/91/6/e599.full\#ref-list-1

This article, along with others on similar topics, appears in the following collection(s):

\section{DWI}

http://n.neurology.org/cgi/collection/dwi

MRI

http://n.neurology.org/cgi/collection/mri

Stroke in young adults

http://n.neurology.org/cgi/collection/stroke_in_young_adults

Information about reproducing this article in parts (figures,tables) or in its entirety can be found online at:

http://www.neurology.org/about/about_the_journal\#permissions

Information about ordering reprints can be found online:

http://n.neurology.org/subscribers/advertise

Neurology ${ }^{\circledR}$ is the official journal of the American Academy of Neurology. Published continuously since 1951, it is now a weekly with 48 issues per year. Copyright @ 2018 American Academy of Neurology. All rights reserved. Print ISSN: 0028-3878. Online ISSN: 1526-632X.

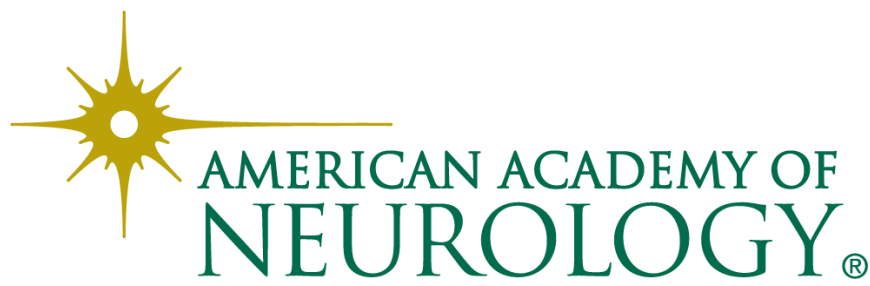

